\title{
Influence of dielectric layer thickness on charge injection, accumulation and transport phenomena in thin silicon oxynitride layers: a nanoscale study
}

\author{
F. Mortreuil, L. Boudou, K. Makasheva, G. Teyssedre and C. Villeneuve-Faure*
}

LAPLACE (Laboratoire Plasma et Conversion d'Energie), Université de Toulouse; CNRS UPS, INPT; 118 route de Narbonne, F-31062 Toulouse cedex 9, France.

*Corresponding author: christina.villeneuve@laplace.univ-tlse.fr

\begin{abstract}
Charge injection and retention in thin dielectric layers remain critical issues due to the great number of failure mechanisms they inflict. Achieving a better understanding and control of charge injection, trapping and transport phenomena in thin dielectric films is of high priority aiming at increasing lifetime and improving reliability of dielectric parts in electronic and electrical devices. Thermal silica is an excellent dielectric but for many of the current technological developments more flexible processes are required for synthesizing high quality dielectric materials such as amorphous silicon oxynitride layers using plasma methods. In this article, the studied dielectric layers are plasma deposited $\mathrm{SiO}_{\mathrm{x}} \mathrm{N}_{\mathrm{y}}$. Independently on the layer thickness, they are structurally identical: optically transparent, having the same refractive index, equal to the one of thermal silica. Influence of the dielectric film thickness on charging phenomena in such layers is investigated at nanoscale using Kelvin Probe Force Microscopy (KPFM) and Conductive Atomic Force Microscopy (C-AFM). The main effect of the dielectric film thickness variation concerns the charge flow in the layer during the charge injection step. According to the $\mathrm{SiO}_{\mathrm{x}} \mathrm{N}_{\mathrm{y}}$ layer thickness two distinct trends of the measured surface potential and current are found, thus defining ultrathin (up to $15 \mathrm{~nm}$ thickness) and thin $(15 \mathrm{~nm}-150 \mathrm{~nm}$ thickness) layers. Nevertheless, analyses of KPFM surface potential measurements associated with results from Finite Element Modelling of the structures show that the dielectric layer thickness has weak influence on the amount of injected charge and on the decay dynamics, meaning that pretty homogeneous layers can be processed. The charge penetration depth in such dielectric layers is evaluated to $10 \mathrm{~nm}$ regardless the dielectric thickness.
\end{abstract}

Keywords: thin film, dielectric, plasma deposition, charge injection, Kelvin Probe Force Microscopy, space charge 


\section{Introduction}

Common property of the dielectric materials is to accumulate charges under external stress, either electric field or particle beam irradiation. Charge accumulation phenomena occur in any dielectric regardless its dimensions (centimeter or nanometer scale) inducing inhomogeneous internal electric field. Even though this effect lies down the principle of operation of a large number of applications as non-volatile memory devices [1,2] it causes dielectric troubleshoots in other devices like electrostatic adhesion in MicroElectroMechanical System (MEMS) [3] or induces damages in electronic devices through uncontrolled electrostatic discharges [4]. Thus, the dielectric charging phenomenon appears as one of the major challenges to meet for many electrical systems. The mechanisms of charge injection and accumulation in dielectric layers remain constantly a subject of scientific research aiming at a better managing of this phenomenon and controlling the level of electrostatic charging of the dielectric layers $[1,2,5$ 7]. However, major advances on the matter can be expected after development of appropriate diagnostic to probe charge injection and decay in thin dielectric layers.

During the past decades, a lot of experimental techniques have been developed to measure space charge distribution as function of the depth in the dielectric and the question of their adaptation to thin dielectrics was raised $[8,9]$. These techniques, based on acoustic or thermal interaction with electrical charges, provide charge density distribution in thick polymer films (thickness from few tens up to few cents of micrometers) with spatial resolution approaching $1 \mu \mathrm{m}$ but they fail to probe charge injection and decay mechanisms in thin dielectric films (thickness in the nanoscale range) used in electronic or microsystems components. Moreover, when the layer thickness scales down the micrometer range, specific issues like interfaces or transition between amorphous and crystalline domains in the dielectric, especially for insulating polymers, are superimposed [10].

Aiming at a study of the charges distribution in thin dielectric films, techniques derived from Scanning Probe Microscopy (SPM) have naturally emerged to inject locally charges and to image the resulting surface potential modification. In this case, the Atomic Force Microscope (AFM) tip is used to perform local charge injection in dielectric materials, followed by measurements of the induced resonance frequency shift by Electrostatic Force Microscopy (EFM) [11-14] or by the resulting surface potential in Kelvin Probe Force Microscopy (KPFM) $[5,11,15]$. Literature overview emphasizes that charge injection and decay in thin dielectric films were extensively studied by EFM and KPFM focusing on charge density determination $[16,17]$, influence of the experimental conditions (humidity [5, 11, 18], lift height [19] or perturbation introduced by the electrostatic forces [20, 21]), or charge dynamics [11, 19]. In 
spite of the numerous investigations on the problem, many aspects as charges distribution within the layer, mechanisms occurring at the metal/dielectric interface or charge injection mechanisms remain currently ill described. Besides, the AFM techniques can bring complementary information on the dielectric charging phenomenon. For example, low-current measurements in thin dielectric layers can be performed by conductive-AFM (C-AFM) or Tunneling AFM (TUNA) [22]. Two aspects can be thus investigated: (i) dielectric reliability in terms of breakdown [23] or leakage current [24] and (ii) mechanisms occurring during charge injection and transport. It was demonstrated for ultrathin $\mathrm{SiO}_{2}$ layer (less than $4 \mathrm{~nm}$ ) that Fowler-Nordheim mechanism $[23,25]$ can be extracted from current versus voltage curves. However, determination of some physical parameters as energy barrier or in-depth charge distribution remains strongly correlated to the tip-sample surface contact estimation [25-29] and requires alternative approaches.

This paper is dedicated to an experimental study of the influence of dielectric layer thickness on charge injection and transport in thin amorphous silicon oxynitride layers. This well-characterized material $[30,31]$, elaborated by plasma process, presents electrical properties very close to those of thermal silica which makes it perfect model material. Surface potential measurements achieved by KPFM and current measurements performed by C-AFM are combined to better understand charge injection mechanisms in thin dielectric films. The paper is organized as follows: the experimental details are presented in section 2. Section 3 is dedicated to results and discussion focusing successively on the $\mathrm{SiO}_{\mathrm{x}} \mathrm{N}_{\mathrm{y}}$ layers characterization, the influence of dielectric thickness on charge injection mechanism and the amount of injected charges, the current versus voltage characteristics recorded by C-AFM, and the charge dynamics after injection. Finally, Section 4 summarizes the main conclusions.

\section{Experimental}

Plasma processed amorphous silicon oxynitride layers $\left(\mathrm{SiO}_{\mathrm{x}} \mathrm{N}_{\mathrm{y}}\right)$ with very low $\mathrm{N}$-content (of only 4 at. \%) have been chosen for this study because of their outstanding electrical properties, close to those of thermal silica, and the possibility to well-control their thickness [30]. The dielectric layers were deposited by Pulsed Plasma Enhanced Chemical Vapor Deposition (PPECVD) in a radio-frequency (RF) capacitively coupled discharge sustained at low gas pressure. The parameters of the plasma process are summarized in Table 1. The gas mixture was of $\mathrm{He}, \mathrm{SiH}_{4}$ and $\mathrm{N}_{2} \mathrm{O}$, with helium as a vector gas (39.7\% of the total gas flow). The $\mathrm{N}_{2} \mathrm{O}$ content was high, in order to achieve good quality silica layers. The RF discharge was modulated with square pulses to avoid dust formation in the plasma and to improve quality of 
the deposited layers, thus their dielectric properties. The arrangement of the dielectric matrix, and accordingly the quality of deposited silica layers was further improved by the very slow deposition process and the high temperature of the substrate during deposition. More details on the plasma process are presented elsewhere [30,31].

Table 1. Parameters of the plasma process for deposition of $\mathrm{SiO}_{\mathrm{x}} \mathrm{N}_{\mathrm{y}}$-layers and the dry oxidation process for growth of thermal $\mathrm{SiO}_{2}$-base.

\begin{tabular}{|l|l|}
\hline \multicolumn{2}{|l|}{ Plasma conditions for deposition of $\mathrm{SiO}_{\mathrm{x}} \mathrm{N}_{\mathrm{y}}$-layers } \\
\hline RF frequency & $13.56 \mathrm{MHz}$ \\
\hline Applied power & $5 \mathrm{~W}$ \\
\hline Pulse period & $400 \mathrm{~ms}$ \\
\hline Pulse width & $100 \mathrm{~ms}$ \\
\hline Total pressure & $65 \mathrm{~Pa}$ \\
\hline Total gas flow & $201.2 \mathrm{sccm}$ \\
\hline He flow & $80 \mathrm{sccm}$ \\
\hline $\mathrm{N}_{2} \mathrm{O}$ flow & $120 \mathrm{sccm}$ \\
\hline SiH flow & $1.2 \mathrm{sccm}$ \\
\hline Precursor ratio, $\gamma=\left[\mathrm{N}_{2} \mathrm{O}_{4} /\left[\mathrm{SiH}_{4}\right]\right.$ & 100 \\
\hline Deposition rate & $3.9 \mathrm{~nm} / \mathrm{min}$ \\
\hline Substrate temperature & $300^{\circ} \mathrm{C}$ \\
\hline \multicolumn{2}{|l}{} \\
\hline Dry oxidation conditions for growth of thermal \\
\hline Total pressure & $1030 \mathrm{hPa}$ \\
\hline Gas mixture & $\mathrm{N}_{2}-\mathrm{O}_{2}$ \\
\hline $\mathrm{O}_{2}$-content & $1 \%$ \\
\hline Temperature & $1100^{\circ} \mathrm{C}$ \\
\hline
\end{tabular}

The structure of the studied devices is shown in figure 1 . The basis consists of a $50 \mathrm{~nm}$ thick $\mathrm{SiO}_{2}$ layer thermally grown on $\mathrm{Si}$ (100) intrinsic substrates by dry oxidation. The parameters of the dry oxidation process are given in Table 1. $70 \mathrm{~nm}$-thick Au/Ti-electrodes (60 $\mathrm{nm}$ of $\mathrm{Au}$ and $10 \mathrm{~nm}$ of Ti with the Ti-layer used as adhesion layer) were processed by sputtering on top of the basis $\mathrm{SiO}_{2}$ by sputtering. Two kinds of metal electrodes were designed: large square plate $\left(4 \times 4 \mathrm{~mm}^{2}\right)$ floating electrode for charge injection study (figure 1(a)) and small wire (40 $\mu \mathrm{m}$ width and $1 \mathrm{~mm}$ long) localized electrode for current measurements (figure 1(b)). Top view of the wire electrode is shown on the Scanning Electron Microscopy image (figure 1(c)). To embed the metal electrodes at different depths the structures were covered by 
$\mathrm{SiO}_{\mathrm{x}} \mathrm{N}_{\mathrm{y}}$ dielectric layers with different thicknesses as top layers. The thickness of the dielectric top $\mathrm{SiO}_{\mathrm{x}} \mathrm{N}_{\mathrm{y}}$-layers was controlled by the deposition time according to the characteristic for the system low deposition rate. After the $\mathrm{SiO}_{\mathrm{x}} \mathrm{N}_{\mathrm{y}}$ deposition a small opening in the top dielectric layer was made to reach the Au-electrode for the current measurements (figures 1(b) and 1(c)).

Spectroscopic ellipsometry was used to measure the dielectric layer thicknesses according to the procedure developed earlier [31]. A SOPRA GES-5 ellipsometer with a rotating polarizer and a fixed analyzer was used in the spectral range $250-850 \mathrm{~nm}$. The simulation of the recorded spectra was performed with Winelli software provided by SOPRA LAB [32]. Forouhi-Bloomer dispersion law was applied for the spectra processing [33]. This approximation applies for dielectric and semiconducting thin layers and provides information on the layer thickness and optical properties ( $\mathrm{n}$ - refractive index and $\mathrm{k}$ - extinction coefficient).

AFM measurements were performed using a Bruker Multimode 8 apparatus under controlled environment (without humidity since under $\mathrm{N}_{2}$ atmosphere) to avoid charge dissipation due to the presence of water layer on the sample surface [31]. A silicon AFM tip with PtIr coating (curvature radius $R_{c}=25 \mathrm{~nm}$ and spring constant $\mathrm{k}_{\mathrm{s}}=2.4 \mathrm{~N} / \mathrm{m}$ ) was used for the charge injection protocol and for the surface potential measurements by KPFM. The dielectric charging was achieved in contact mode (contact force set to $90 \mathrm{nN}$ ) by applying positive DC bias $\left(\mathrm{V}_{0}=+5\right.$ to $\left.+15 \mathrm{~V}\right)$ to the AFM tip for different time durations, the sample back side being grounded (figure 1(a)). After the charging step, the same tip was used to probe the surface potential in Amplitude Modulation KPFM mode using a $10 \mathrm{~nm}$-lift.

Current measurements were performed with a diamond coated highly doped Si tip $\left(\mathrm{R}_{\mathrm{c}}=125 \mathrm{~nm}\right.$ and $\left.\mathrm{k}_{\mathrm{s}}=2 \mathrm{~N} / \mathrm{m}\right)$ using C-AFM mode (figure 1(b)). A bias varying between $+1 \mathrm{~V}$ and $+20 \mathrm{~V}$ was applied to the Au-electrode. In order to adapt the noise detection level, the current measurements were performed owing to a low noise amplifier module, with $20 \mathrm{pA}$ sensitivity for the dielectric layers thicker than $15 \mathrm{~nm}$ and $10 \mathrm{nA}$-sensitivity for lower thicknesses. Current was acquired during $60 \mathrm{~s}$ for each bias. 

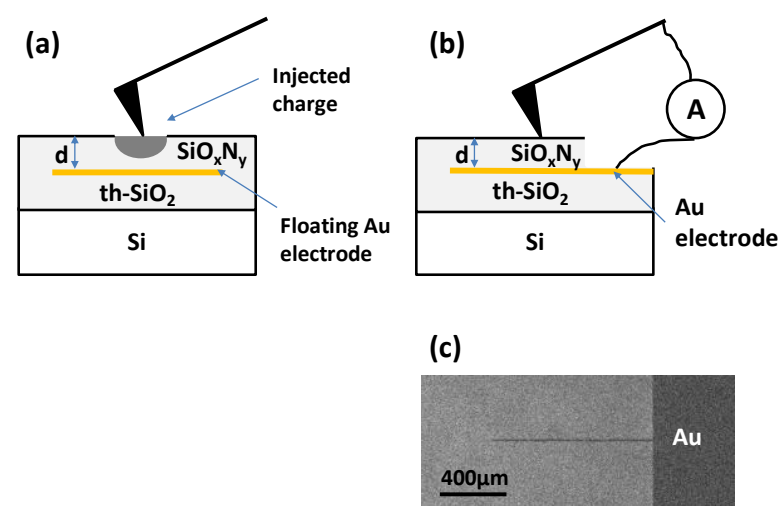

Figure 1. The studied device is composed of thermal $\mathrm{SiO}_{2}$ base, Au electrode and $\mathrm{SiO}_{\mathrm{x}} \mathrm{N}_{\mathrm{y}}$-layer over $\mathrm{Si}$ substrate. Device configuration for (a) charge injection and decay measurements and (b) C-AFM measurement; (c) Scanning Electron Microscopy top view image of the Au-electrode embedded at $31 \mathrm{~nm}$ for the current measurements.

\section{Results and discussion}

\subsection{Dielectric layer characterization}

The thickness and optical parameters of the plasma deposited $\mathrm{SiO}_{\mathrm{x}} \mathrm{N}_{\mathrm{y}}$ layers were systematically measured by spectroscopic ellipsometry. The $\mathrm{SiO}_{\mathrm{x}} \mathrm{N}_{\mathrm{y}}$-layers span in the thickness range from ultrathin, i.e. up to $15 \mathrm{~nm}(5.9 \pm 0.4 \mathrm{~nm}$ and $11.1 \pm 0.9 \mathrm{~nm})$ to thin, $15 \mathrm{~nm}<d<150 \mathrm{~nm}(15.6$ $\pm 0.4 \mathrm{~nm}, 31.1 \pm 0.2 \mathrm{~nm}, 50.0 \pm 0.2 \mathrm{~nm}, 68.0 \pm 0.3 \mathrm{~nm}, 129.7 \pm 0.8 \mathrm{~nm})$, layers. They are all transparent with extinction coefficient $\mathrm{k}<0.002$ in the investigated spectral range, having refractive index $n=1.45 \pm 0.1$ at wavelength $\lambda=632.8 \mathrm{~nm}$ (figure 2) which qualifies them as layers with optical properties very close to thermal silica layers. Using the Forouhi-Bloomer dispersion law for spectra processing allows for extraction of the layer thickness and the optical properties in a consistent way. It avoids overestimation of the layer thickness when the refractive index of bulk silica is applied for simulation of the recorded ellipsometric spectra [34]. Regardless the $\mathrm{SiO}_{x} \mathrm{~N}_{y}$-layer thickness the refractive index remains the same (figure 2(a)). We do not observe departure in the optical properties, towards higher refractive index, for the ultrathin $\mathrm{SiO}_{\mathrm{x}} \mathrm{N}_{\mathrm{y}}$-layers as reported for ultrathin $\mathrm{SiO}_{2}$ thermal layers [34]. Conservation of the refractive index for the $\mathrm{SiO}_{\mathrm{x}} \mathrm{N}_{\mathrm{y}}$-layers is most likely due to the plasma deposition process for which the layer growth results from deposition of plasma generated radicals, issued from the injected precursors. The applied for this study pulsed mode of operation of the PPECVD process improved the quality of the deposited layer. It leads to homogeneous distribution of the gas precursors in the reactor between the pulses, before each plasma ignition, which prevents from plasma deposition under O-related by-products exhaust [35]. Thus the PPECVD process allows for better control of the layer stoichiometry $(\mathrm{O} / \mathrm{Si}=2)$, avoiding modifications in the layer composition and structure. 

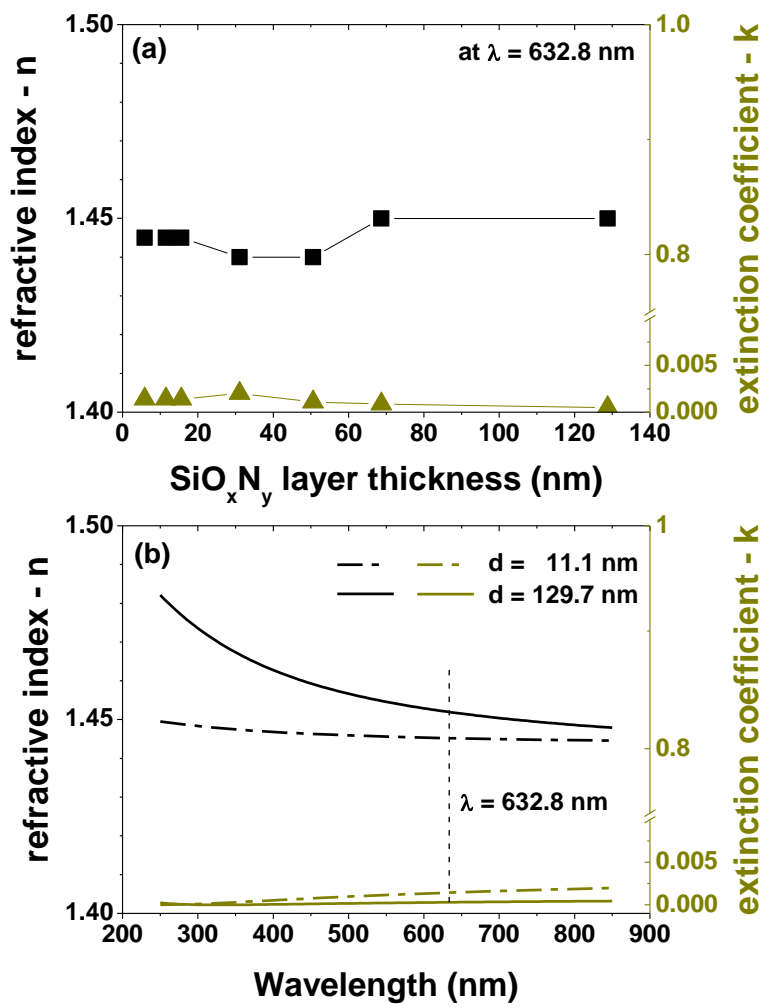

Figure 2. (a) Refractive index and extinction coefficient of the studied $\mathrm{SiO}_{\mathrm{x}} \mathrm{N}_{\mathrm{y}}$ thin dielectric layers as obtained from spectroscopic ellipsometry at $\lambda=632.8 \mathrm{~nm}$, (b) Variation of the refractive index and the extinction coefficient in the studied wavelength range for one ultrathin $\operatorname{SiO}_{\mathrm{x}} \mathrm{N}_{\mathrm{y}}$ layer $(d=11.1 \mathrm{~nm})$ and one thin layer $(d=129.7 \mathrm{~nm})$.

The spectral response of the $\mathrm{SiO}_{\mathrm{x}} \mathrm{N}_{\mathrm{y}}$-layers is closely related to the dielectric structure of the layer. It also gives information on the energy gap and the different charge traps [36]. After processing of the ellipsometry spectra, for all studied here $\mathrm{SiO}_{\mathrm{x}} \mathrm{N}_{\mathrm{y}}$-layers, we have found an electronic part of the dielectric constant of $\varepsilon_{\infty}=2.13\left(\mathrm{n}_{\infty}=1.46\right)$. The later provides a Schottky pinning parameter of $\mathrm{S}_{\mathrm{p}}=0.887$ and defines the charge state in the $\mathrm{SiO}_{\mathrm{x}} \mathrm{N}_{\mathrm{y}}$ dielectric interface as slightly pinned when in contact with a metal electrode [36, 37]. A small increase of the refractive index is observed in the Mid-UV and Near-UV range for the thickest $\mathrm{SiO}_{\mathrm{x}} \mathrm{N}_{\mathrm{y}}$ layer $(d=129.7 \mathrm{~nm}$, in figure 2(b)). In addition to the normal dispersion of the refractive index in that spectral region, the refractive index increase is most likely due to the limited, but present small $\mathrm{N}$-content (4 at. \%) in the $\mathrm{SiO}_{\mathrm{x}} \mathrm{N}_{\mathrm{y}}$-layer.

\subsection{Impact of the dielectric thickness on the charge injection: KPFM study}

For each $\mathrm{SiO}_{\mathrm{x}} \mathrm{N}_{\mathrm{y}}$ layer, charge injection was done under tip bias $\mathrm{V}_{0}$ varying from $+5 \mathrm{~V}$ to $+15 \mathrm{~V}$ during various times (from $1 \mathrm{~min}$ to $10 \mathrm{~min}$ ). Immediately after charge injection, the KPFM 
surface potential profiles were recorded along a line crossing the injection point (figure 3) [31]. Figure 3(a) represents the surface potential induced by the injected charges. The potential distribution is of round shape. AFM mapping of the $\mathrm{SiO}_{\mathrm{x}} \mathrm{N}_{\mathrm{y}}$-surface in the region of charge injection shows no modification of the $\mathrm{SiO}_{\mathrm{x}} \mathrm{N}_{\mathrm{y}}$-surface topography (figure 3(b)). A classical Gaussian shape of the potential profile is observed (figure 3(c)). Three relevant parameters were extracted from this profile: (i) The maximum potential $\mathrm{V}_{\mathrm{m}}$, with respect to surface reference potential, which is measured at the injection point; (ii) The Full Width at Half Maximum (FWHM) which reflects the charges lateral spreading and (iii) The area Is under the potential profile which is considered to represent, to a first approximation, the quantity of stored charges. The later assumption is considered valid even for thin dielectric films because the injected charges remain close to the surface. The evolution of these three parameters, as function of the charge injection conditions, was investigated to follow the charge injection and transport dynamics. The reference potential in figure 3(c) corresponds to the potential of the surface prior to charge injection. Reproducibility measurements show very low variation in the probed values of the potential profile, thus the extracted parameters. Standard deviation of the potential maximum does not exceed $8 \%$ and the one of FWHM of the potential profile is limited to $4 \%$. For clarity issues errors bars are not represented on the figures later on.
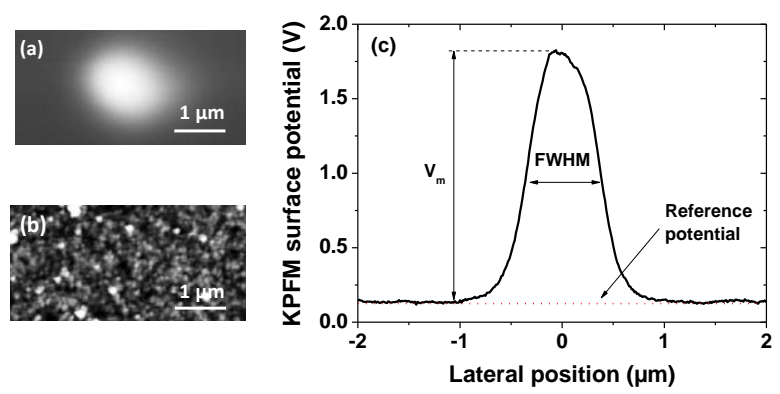

Figure 3. AFM mapping of the $\mathrm{SiO}_{\mathrm{x}} \mathrm{N}_{\mathrm{y}}$-surface in the region of charge injection $\left(2\right.$ min at $\left.\mathrm{V}_{0}=+12 \mathrm{~V}\right)$ for the 130 nm-thick layer: (a) potential distribution and (b) $\mathrm{SiO}_{x} \mathrm{~N}_{y}$ surface topography. (c) KPFM surface potential profile.

Figure 4(a) represents the evolution of the surface potential profile as function of the film thickness for charge injection at $+12 \mathrm{~V}$ during $2 \mathrm{~min}$. One can distinguish two different trends with respect to the dielectric layer thickness.

- Dielectric layers with thickness less than $15 \mathrm{~nm}$ (ultrathin layers): FWHM and area IS increase with the dielectric layer thickness even though the electric field decreases (constant bias voltage). 
- Dielectric layers with thickness larger than $15 \mathrm{~nm}$ (thin layers): FWHM and area $\mathrm{I}_{\mathrm{S}}$ are insensitive to the dielectric layer thickness.

The influence of the dielectric thickness on the evolution of the maximum potential $\mathrm{V}_{\mathrm{m}}$ and area IS as function of the injection time for different $\mathrm{SiO}_{\mathrm{x}} \mathrm{N}_{\mathrm{y}}$-layer thicknesses is presented in figure 4(b). As previously, different behaviors are observed as function of the dielectric layer thickness for ultrathin and thin layers. For the $11 \mathrm{~nm}$-thick $\mathrm{SiO}_{\mathrm{x}} \mathrm{N}_{\mathrm{y}}$-layer, $\mathrm{IS}_{\mathrm{S}}$ and $\mathrm{V}_{\mathrm{m}}$ remain relatively constant regardless the injection time. The $31 \mathrm{~nm}$-thick $\mathrm{SiO}_{\mathrm{x}} \mathrm{N}_{\mathrm{y}}$ behaves differently for short and longer injection times. For short times (less than $5 \mathrm{~min}$ ), $\mathrm{V}_{\mathrm{m}}$ and $\mathrm{I}_{\mathrm{S}}$ increase with injection time. For longer injection times a saturation in the two parameters is observed. As for the $130 \mathrm{~nm}$ thick $\mathrm{SiO}_{\mathrm{x}} \mathrm{N}_{\mathrm{y}}$-layer, the $\mathrm{V}_{\mathrm{m}}$ and $\mathrm{I}_{\mathrm{S}}$ increase with the injection time but the FWHM (not shown vs. charging time) of the potential profile is slightly influenced by the injection time. It increases by only $0.1 \mu \mathrm{m}$, from $0.4 \mu \mathrm{m}$ for $1 \mathrm{~min}$ charging time to $0.5 \mu \mathrm{m}$ for $10 \mathrm{~min}$.
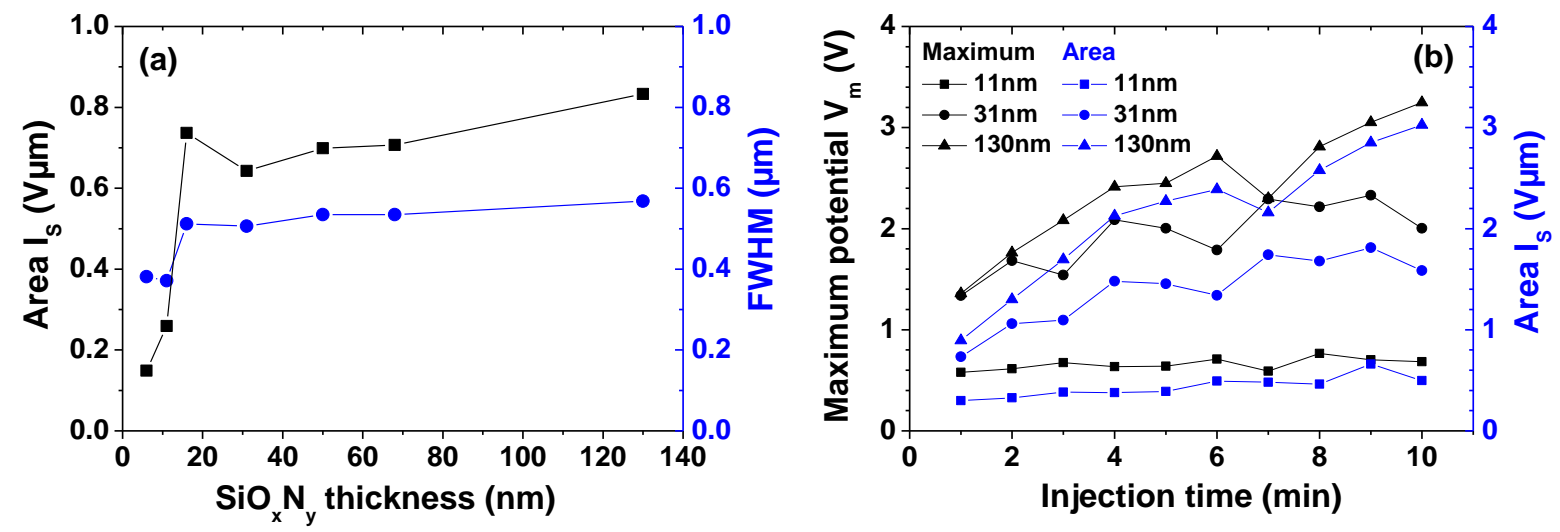

Figure 4. (a) Evolution of the surface potential profile FWHM and area $\mathrm{I}_{\mathrm{S}}$ as function of the $\mathrm{SiO}_{\mathrm{x}} \mathrm{N}_{\mathrm{y}}$-layer thickness for constant injection time and bias $\left(2 \mathrm{~min}\right.$ at $\mathrm{V}_{0}=+12 \mathrm{~V}$ ); (b) Evolution of the surface potential maximum $\mathrm{V}_{\mathrm{m}}$ and the area $\mathrm{I}_{\mathrm{S}}$ under peak as function of the injection time for $\mathrm{SiO}_{\mathrm{x}} \mathrm{N}_{\mathrm{y}}$-layers with different thicknesses (applied bias of $\left.\mathrm{V}_{0}=+12 \mathrm{~V}\right)$.

The same evolution of the surface potential profile is observed when increasing the injection bias for a fixed injection time (results not shown). Indeed, the $V_{m}$ and $I_{S}$ are insensitive to the injection bias increase for charge injection in the $11 \mathrm{~nm}$-thick film, whereas these two parameters increase with increasing the bias for charge injection in the $130 \mathrm{~nm}$-thick dielectric film. Concerning the $31 \mathrm{~nm}$-thick film, again a two steps behavior is observed: the increase of $\mathrm{V}_{\mathrm{m}}$ and $\mathrm{Is}_{\mathrm{S}}$ with increasing the injection bias is followed by saturation (for applied bias larger than $+8 \mathrm{~V})$. However, the relationship between the area and the amount of injected charges is not straightforward in this case because of the dielectric layer thickness. This aspect will be discussed in detail in the following sections. 


\subsection{Electric field influence on the charge injection: modeling approach}

Results presented in the previous part show different fate of the injected charges depending on the dielectric layer thickness. To better understand the underlying mechanisms, we have performed an electrostatic modelling of the system aiming at identification of the relative contribution of the electric field components during charge injection and the influence of dielectric layer thickness on the surface potential profile.

The electric field is computed using a simple model consisting in a truncated cone of $10 \mu \mathrm{m}$-height with $14^{\circ}$ aperture angle, ending with a semi-spherical apex of $\mathrm{R}_{\mathrm{c}}=25 \mathrm{~nm}$ or $R_{c}=125 \mathrm{~nm}$. The considered geometry corresponds to a classical AFM tip shape used for modelling [38]. It accounts for the macroscopic shape of the tip, rather than the nanoscopic shape of the tip apex due to the long range nature of the electrostatic forces [39]. This tip is surrounded by an air box (dimensions large enough to avoid edge effects). It is in contact with the dielectric $\mathrm{SiO}_{\mathrm{x}} \mathrm{N}_{\mathrm{y}}$ layer (figure 5(a)). The Au-electrode is considered at floating potential. Potential and electric field are computed in air, $\mathrm{SiO}_{\mathrm{x}} \mathrm{N}_{\mathrm{y}}, \mathrm{SiO}_{2}$ layers and in the intrinsic Sisubstrate. The electric field is supposed capacitively distributed considering the relatively short polarization times used here and the large dielectric time constant for the dielectric layers. The relative dielectric permittivity of the $\mathrm{SiO}_{\mathrm{x}} \mathrm{N}_{\mathrm{y}}$ layer is taken $\varepsilon_{\mathrm{r}}=3.9$, as measured by dielectric spectroscopy for the very same dielectric layers [30]. For the thermal $\mathrm{SiO}_{2}$ and the $\mathrm{Si}$-substrate it is $\varepsilon_{\mathrm{r}}=3.9$ and 12 , respectively. The model is 2D-axisymmetric based on Finite-Element Model (FEM) developed on COMSOL Multiphysics. The mesh is refined and optimized close to the contact point to improve calculation accuracy. The potential is applied on the tip and the ground is taken at the silicon substrate backside (charge injection configuration). The dielectric is supposed free from charges at the initial state. The boundary conditions are selected to ensure no edge effect and no charges (zero potential) on the free boundaries of the simulation box.

The Poisson's equation is solved in air and in the dielectric layers to determine the potential $\mathrm{V}$.

$$
\vec{\nabla} \cdot\left(\varepsilon_{0} \varepsilon_{r} \vec{E}\right)=\rho
$$

where $\rho$ is the charge density and $\varepsilon_{0}$ is the vacuum permittivity.

The electric field $\vec{E}$ is derived from the potential V:

$$
\vec{E}=-\vec{\nabla} V
$$



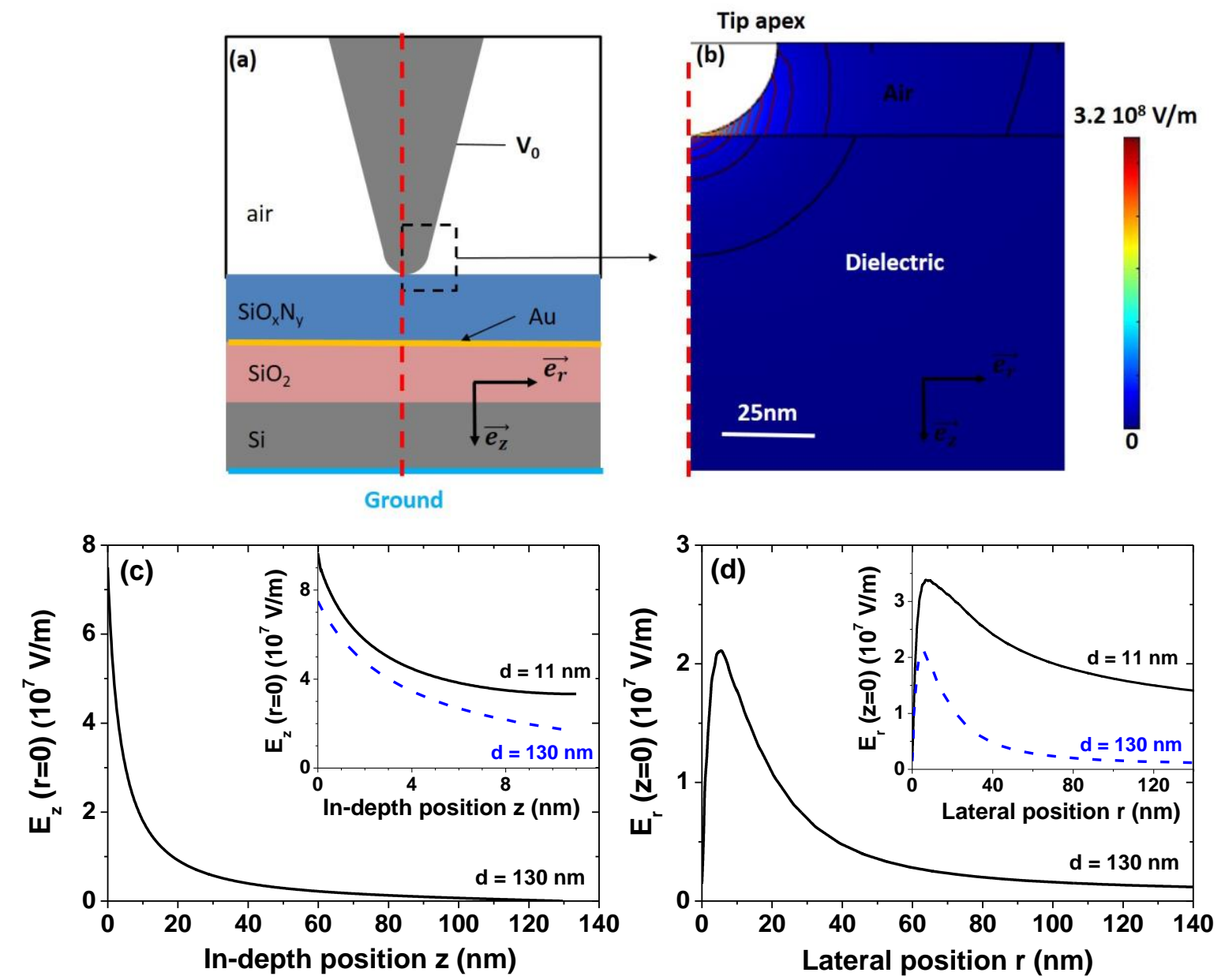

Figure 5. (a) Scheme of the AFM tip and the sample system, (b) Spatial distribution of computed electric field modulus for $\mathrm{V}_{0}=+10 \mathrm{~V}$ applied to the tip during charging protocol $\left(\mathrm{R}_{\mathrm{c}}=25 \mathrm{~nm}\right)$ for the $130 \mathrm{~nm}$-thick dielectric layer, (c) Related $E_{z}$ electric field in-depth distribution of the $130 \mathrm{~nm}$-thick dielectric layer. In insert, the $E_{z}$ indepth distribution of the $130 \mathrm{~nm}$-thick and the $11 \mathrm{~nm}$-thick dielectric layer for the same $\mathrm{V}_{0}$ and (d) the lateral $E_{r}$ electric field distribution at the dielectric/air interface-of the $130 \mathrm{~nm}$-thick dielectric layer. In insert, the lateral $\mathrm{E}_{\mathrm{r}}$ distribution of the $130 \mathrm{~nm}$-thick and the $11 \mathrm{~nm}$-thick dielectric layer for the same $\mathrm{V}_{0}$.

The electric field distribution in the $130 \mathrm{~nm}$-thick $\mathrm{SiO}_{\mathrm{x}} \mathrm{N}_{\mathrm{y}}$ dielectric layer for a bias of $\mathrm{V}_{0}=+10 \mathrm{~V}$ applied to the tip in charge injection configuration is depicted in figure 5(b). The electric field is non-homogeneously distributed in the dielectric layer. An electric field strengthening is observed at the contact point under the tip. The electric field is substantially enhanced close to the injection area compared to the electric field strength in plane-plane configuration for the same dielectric thickness.

The in-depth evolution of the $\mathrm{E}_{\mathrm{z}}$-component of the electric field along the revolution axis is represented in figure 5(c) for the $130 \mathrm{~nm}$-thick and the $11 \mathrm{~nm}$-thick (insert of figure 5(c)) dielectric layers. The $\mathrm{E}_{\mathrm{z}}$-field decreases exponentially in the $130 \mathrm{~nm}$-thick dielectric layer. The $\mathrm{E}_{\mathrm{z}}$-field decrease is reduced in the $11 \mathrm{~nm}$-thick layer. The more homogeneous in-depth 
distribution of the electric field in the $11 \mathrm{~nm}$-thick layer is explained by the fact that for dielectric layers with thicknesses smaller than the AFM tip radius, the configuration gets closer to a planeplane one. In our configuration this effect is ensured by the Au layer, which screens the electric field, and diminishes the influence of the thermal $\mathrm{SiO}_{2}$ layer and the intrinsic $\mathrm{Si}$ bulk. The evolution of the lateral $\mathrm{E}_{\mathrm{r}}$-component of the electric field along the dielectric surface is represented in figure $5(\mathrm{~d})$ for the $130 \mathrm{~nm}$-thick and the $11 \mathrm{~nm}$-thick (insert of figure $5(\mathrm{~d})$ ) dielectric layers. One can notice that the maximum lateral electric field is less influenced by the thickness of the dielectric layer whereas a profile broadening is observed for the thinner layer. This high lateral electric field drives the charges spreading in radial direction.

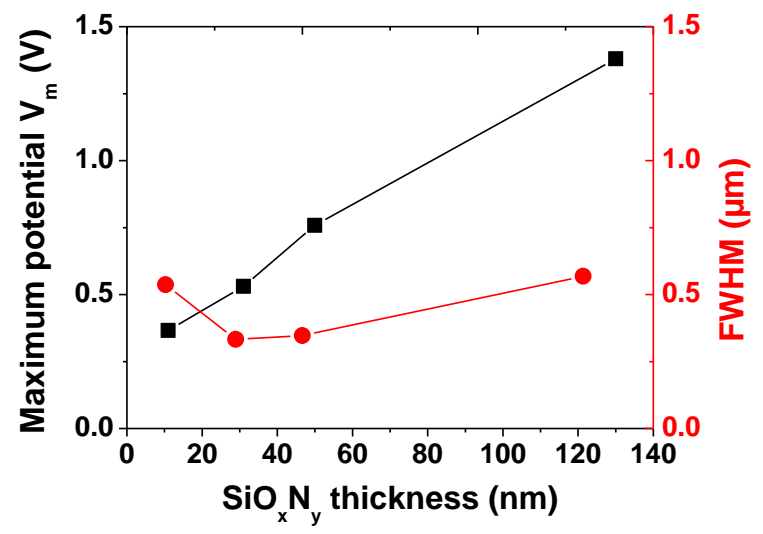

Figure 6. Evolution of surface potential maximum $\mathrm{V}_{\mathrm{m}}$ and $\mathrm{FWHM}$ as function of the $\mathrm{SiO}_{\mathrm{x}} \mathrm{N}_{\mathrm{y}}$ film thickness for an electric field at the injection point of $4.7 \times 10^{7} \mathrm{~V} / \mathrm{m}$ (injection time of $2 \mathrm{~min}$ ).

The strong inhomogeneity of the electric field, especially for thin $\mathrm{SiO}_{\mathrm{x}} \mathrm{N}_{\mathrm{y}}$-layers $(d>15 \mathrm{~nm})$ prevents from correct interpretation of the measured surface potential on films of different thicknesses, as the electric field at the contact point is different. For comparison reasons figure 6 represents the variation of the surface potential maximum $V_{m}$ and FWHM as function of the film thickness for the same initial electric field at the injection point, as calculated from the above described model. The FWHM does not vary significantly with the dielectric layer thickness. This is most probably related to the fact that the lateral electric field maximum is weakly influenced by the dielectric layer thickness (figure 5(d)). In addition, it is of the order of $0.5 \mu \mathrm{m}$, i.e. significantly larger than the distance from the axis providing maximum radial field. So, the space-charge induced field probably drives the charge spreading more significantly than the geometric field.

The potential maximum $V_{m}$ and consequently the area under the peak $I_{s}$ increases with the film thickness. However, to conclude about possible relation between the charge storage 
capability and the film thickness, the relation between charge amount and surface potential should be determined.

\subsection{Estimation of the injected charge density}

In order to identify the impact of the dielectric layer thickness on the probed surface potential, the previous finite element model was modified. Space charge distribution $\rho$ was introduced in the Poisson's equation. The Gaussian shape of the measured surface potential profile was adopted for the lateral distribution of the injected charges. Nevertheless, different hypotheses can be made for the in-depth distribution of the injected in the dielectric layer charges. Here we have investigated two different in-depth charge distributions:

1) In the first case, the in-depth charge density distribution was supposed constant over a thickness $d_{p}$. The same hypothesis was made by E. Palleau et al. [40]. The resulting charge density profile $\rho_{H}$ is called 2D, depicted on the insert in Figure 7(a), and can be given by the following expression:

$$
\rho_{H}(r, z)=\frac{Q}{d_{p}} \frac{1}{\sigma_{r} \sqrt{2 \pi}} \exp \left(-\frac{r^{2}}{2 \sigma_{r}^{2}}\right) \quad 0 \leq \mathrm{z} \leq d_{p}
$$

where $\mathrm{Q}$ is the injected charge quantity, $d_{p}$ is the charge penetration depth in the dielectric and $\sigma_{\mathrm{r}}$ is a parameter corresponding to the lateral extension of the charge distribution (related to the FWHM, $\mathrm{W}_{\mathrm{r}}=2.35 \sigma_{\mathrm{r}}$ ). The penetration depth $d_{p}$ could be smaller or equal to the dielectric layer thickness. Figure 7(a) illustrates the charge density distribution in a $130 \mathrm{~nm}$-thick dielectric layer for $\mathrm{Q}=1.25 \times 10^{-16} \mathrm{C}, d_{p}=11 \mathrm{~nm}$ and $\mathrm{W}_{\mathrm{r}}=250 \mathrm{~nm}$.

2) In the second case, the in-depth distribution of injected charges is with half-Gaussian shape. The resulting 3D charge density profile $\rho_{G}$, depicted on the insert in figure 7(b), can be given by the following expression:

$$
\rho_{G}(r, z)=2 Q \frac{1}{\pi \sigma_{r} \sigma_{z}} \exp \left(-\frac{r^{2}}{2 \sigma_{r}^{2}}-\frac{z^{2}}{2 \sigma_{z}^{2}}\right) \quad 0 \leq \mathrm{z} \leq d
$$

where $\sigma_{\mathrm{z}}$ is related to the in-depth distribution of injected charges (related to $\mathrm{FWHM} \mathrm{W}_{\mathrm{z}}$ of the full Gaussian with $\mathrm{W}_{\mathrm{z}}=2.35 \sigma_{\mathrm{z}}$ ). The insert in figure $7(\mathrm{~b})$ illustrates the 3D-charge density distribution in the same $130 \mathrm{~nm}$-thick dielectric layer for $\mathrm{Q}=1.25 \times 10^{-16} \mathrm{C}, \mathrm{W}_{\mathrm{z}}=10 \mathrm{~nm}$ (representing the in-depth charge spreading $d_{p}$ ) and $\mathrm{W}_{\mathrm{r}}=250 \mathrm{~nm}$. 
(a)

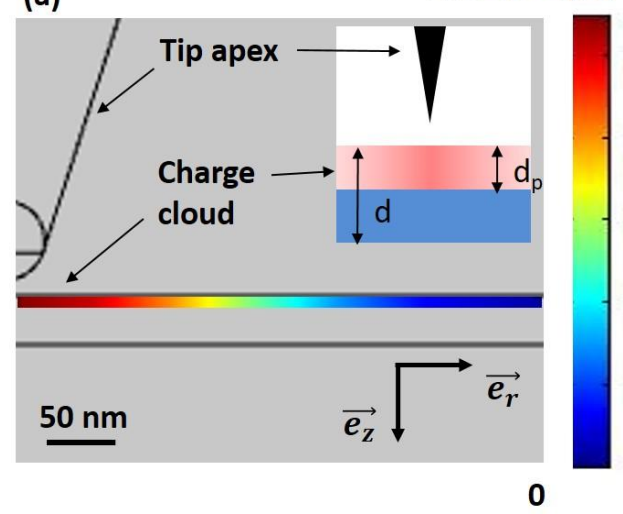

(b)

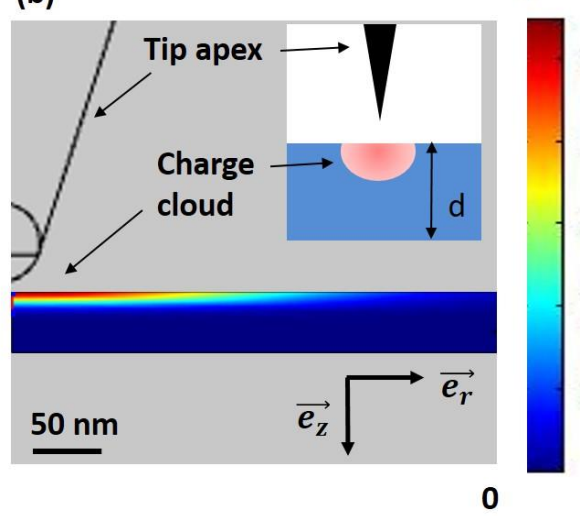

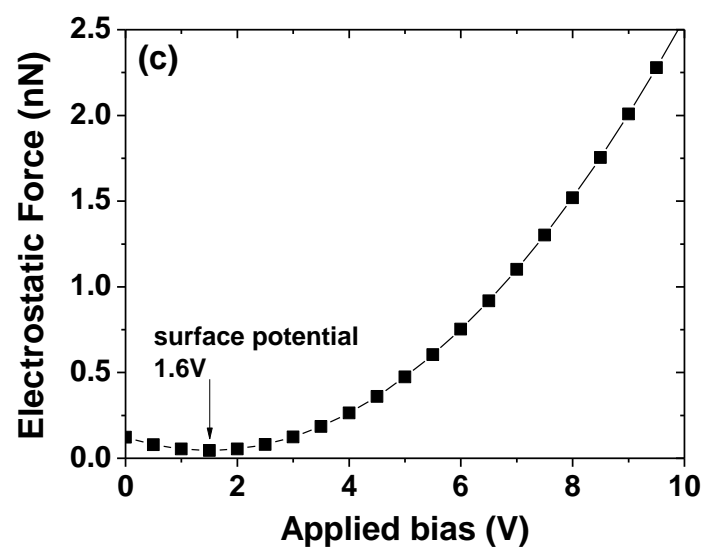

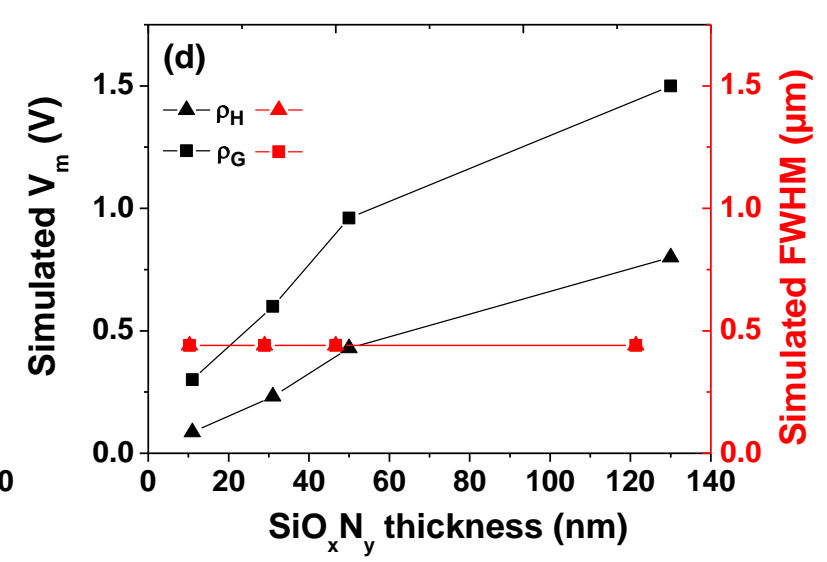

Figure 7. Charge distribution in the FEM model for (a) $2 \mathrm{D} \rho_{H}$ and (b) $3 \mathrm{D} \rho_{G}$ charge density distributions, AFM probe is lifted at $10 \mathrm{~nm}$ as for KPFM measurements. (c) Evolution of electrostatic force as function of the applied bias on the tip for $130 \mathrm{~nm}$-thick $\mathrm{SiO}_{\mathrm{x}} \mathrm{N}_{\mathrm{y}}$ layer and $2 \mathrm{D}$ charge density $\rho_{H}\left(\mathrm{Q}=1.25 \times 10^{-16} \mathrm{C}, d_{p}=11 \mathrm{~nm}\right.$ and $\mathrm{W}_{\mathrm{r}}=250 \mathrm{~nm}$ ), (d) Evolution of computed maximum potential and FWHM of the potential profile as function of the $\mathrm{SiO}_{\mathrm{x}} \mathrm{N}_{\mathrm{y}}$-layer thickness for the two charge density profiles $2 \mathrm{D} \rho_{H}$ and $3 \mathrm{D} \rho_{G}\left(\mathrm{~W}_{\mathrm{z}}=10 \mathrm{~nm}\right.$ and $\left.\mathrm{W}_{\mathrm{r}}=250 \mathrm{~nm}\right)$.

To obtain the surface potential profile, the electrostatic force $F_{e}$ induced on the tip by the charge cloud was computed using the following equation:

$$
F_{e}=\iint_{t i p} \frac{\varepsilon_{0} \varepsilon_{r}}{2}\|\vec{E}\|^{2} d S
$$

where $\mathrm{E}$ is the electric field, $\varepsilon_{\mathrm{r}}=1$ is the air relative dielectric permittivity and $\mathrm{dS}$ is an elementary surface. At each point, the electrostatic force $F_{e}$ is computed as function of the applied bias $\mathrm{V}_{0}$. Thus a parabolic curve, as the one shown in figure 7(c), is obtained and the related surface potential corresponds to the electrostatic force minimum [16].

Concerning the 2D-charge distribution $\rho_{H}$ : the surface potential profile was computed with the same charge parameters as above $\left(\mathrm{Q}=1.25 \times 10^{-16} \mathrm{C}, d_{p}=11 \mathrm{~nm}\right.$ and $\left.\mathrm{W}_{\mathrm{r}}=250 \mathrm{~nm}\right)$ for different dielectric layer thicknesses. The resulting maximum surface potential and the FWHM are depicted as function of the dielectric thickness on figure 7(d). The obtained results 
emphasize that, for the studied 2D-charge distribution, the resulting surface potential maximum increases with the dielectric film thickness, whereas the FWHM remains constant.

Concerning the 3D-charge distribution $\rho_{G}$ : again the surface potential profile was computed with the charge parameters as for the $2 \mathrm{D}$-charge distribution $\left(\mathrm{Q}=1.25 \times 10^{-16} \mathrm{C}\right.$, $\mathrm{W}_{\mathrm{Z}}=10 \mathrm{~nm}$ and $\mathrm{W}_{\mathrm{r}}=250 \mathrm{~nm}$ ) for different dielectric layer thicknesses. The resulting maximum surface potential and the FWHM are depicted as function of the dielectric thickness on figure 7(d). As previously, the results emphasize that the resulting surface potential maximum increases with dielectric film thickness, whereas the FWHM remains constant. The FWHM is identical for the two charge density profiles $2 \mathrm{D} \rho_{H}$ and $3 \mathrm{D} \rho_{G}$.

Therefore, independently on the considered space charge distribution, for fixed charge distributions, the maximum surface potential increases with the dielectric layer thickness. Moreover, the increase in potential vs. layer thickness obtained in simulation with the $2 \mathrm{D}$ or $3 \mathrm{D}$ charge distribution reproduces the trends in the experimental results presented in figure 6 . According to these simulation results, the increase in potential with the dielectric thickness for fixed injection conditions (field and time) would be explained mainly by electrostatic features and not by a variation in the amount of injected charges. The electric field at the contact point actually determines the charge amount to be injected in the dielectric.

\subsection{Charges dynamic during injection: current measurements}

To go further in the description of charge dynamic during injection, the study on charge injection and surface potential measurements was completed with C-AFM measurements. The C-AFM measurements were performed by using the second device structure (figure 1(b)) and a diamond coated highly-doped Si tip with curvature radius of $\mathrm{R}_{\mathrm{c}}=125 \mathrm{~nm}$. For comparison purposes, the current measurements performed on dielectric films with different thicknesses are presented as function of the electric field at the contact point (figure 8). The electric field at contact point is computed using a FEM model, similar to the one already described in Section 3.3. The main difference is that the bias is applied on the Au-electrode (figure 1(b)) and the tip is grounded, in order to remain consistent with the experimental situation.

As previously noticed, different responses are observed for the ultrathin $(d<15 \mathrm{~nm})$ and the thin $(15 \mathrm{~nm}<d<150 \mathrm{~nm}) \mathrm{SiO}_{\mathrm{x}} \mathrm{N}_{\mathrm{y}}$ films. The measured current for ultrathin layers remains at low current level $(0.14 \mathrm{pA})$ and almost constant for a large range of variation of the electric field up to a threshold value after which a very quick current increase ( 5 orders of magnitude) is observed (figure 8). The thin layers are characterized by a rather slow increase of the current with the electric field, starting at halved current level $(0.07 \mathrm{pA})$ for a fixed electric field and 
increasing by an order of magnitude for the same range of variation of the electric field. The $16 \mathrm{~nm}$-thick $\mathrm{SiO}_{\mathrm{x}} \mathrm{N}_{\mathrm{y}}$ film appears intermediate with a mixed response. No topography modifications were observed on the surface of the studied dielectric layers after the C-AFM measurements.

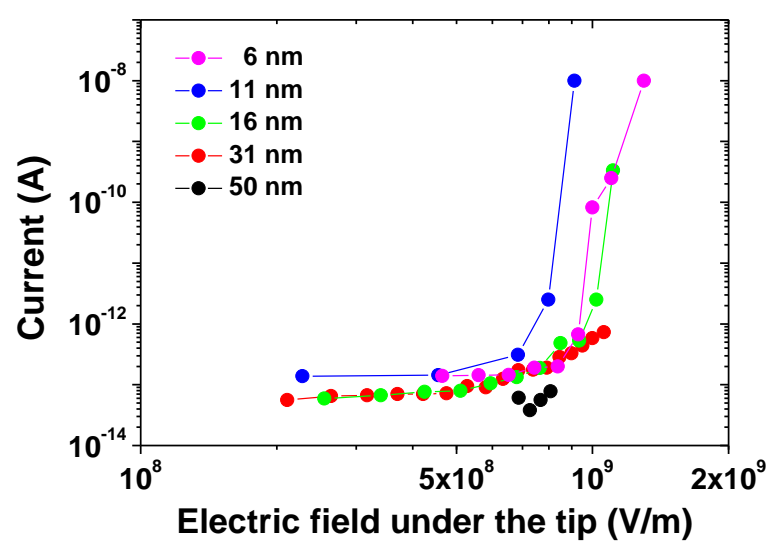

Figure 8. Current versus electric field characteristics for $\mathrm{SiO}_{\mathrm{x}} \mathrm{N}_{\mathrm{y}}$ layers with different thicknesses.

With respect to the current measurements, one can say that Fowler-Nordheim conduction is most likely the mechanism controlling the current in ultrathin layers $[23,25,27,28]$. However, for the interpretation of these results, in term of transport laws, the current density needs to be computed, which requires estimation of the current collection area. Indeed, assessment of the current collection area is the main bottleneck in the analysis of the C-AFM results. In C-AFM mode, the measurement response is closely linked to the physical properties of the contact between the nano-sized tip and the dielectric surface. This interaction was demonstrated for ultrathin inorganic (ceramic) dielectric films and thin organic semiconductor films, by using the Fowler-Nordheim [16, 23, 25, 37-38, 40] and the Space Charge Limited Current law [41], respectively. We also split the analysis here in two, for ultrathin and thin $\mathrm{SiO}_{\mathrm{x}} \mathrm{N}_{\mathrm{y}}$ layers [42].

\section{- Ultrathin dielectric layers $(d<15 \mathrm{~nm})$}

Concerning the ultrathin dielectric layers, the collection area is typically determined by using one of the three main approaches: (i) The contact area is computed using the Hertz approach and corresponds to the mechanical contact area [43], (ii) The effective contact surface is determined by fitting the current-voltage experimental curve. This assessment depends on the following parameters: AFM-tip work function, contact force and dielectric thickness, and leads a broad range of obtained values, from $10 \mathrm{~nm}^{2}$ to $100 \mathrm{~nm}^{2}$ or even more if the curvature radius of the 
AFM-tip is large, and (iii) The contact area is estimated after SEM observations of the AFM tip after measurements [44].

In order to better estimate the effective contact surface for the current measurements we have used a fourth approach. The current versus electric field curve obtained for the $6 \mathrm{~nm}$-thick $\mathrm{SiO}_{\mathrm{x}} \mathrm{N}_{\mathrm{y}}$ layer was fitted using the Fowler-Nordheim Tunneling (FNT) theory. In the frame of FNT the current is given by:

$$
I=S \alpha E^{2} \exp \left(-\frac{\beta}{E}\right)
$$

with $\alpha=\frac{q^{3}}{8 \pi h} \frac{m_{e}}{m_{o x}} \frac{1}{\Phi_{B}}$ and $\beta=\frac{8 \pi}{3} \frac{\sqrt{2 m_{o x}}}{q h} \Phi_{B}^{3 / 2}$. In equation (6) $E$ is the applied field to the dielectric layer, $S$ is the area of the electrodes (when considering a symmetric metal/insulator/metal (MIM) structure; with $\mathrm{R}_{\mathrm{c}}=125 \mathrm{~nm} \gg d=6 \mathrm{~nm}$, the hypothesis for a symmetric MIM structure is fulfilled), $m_{o x}$ is the effective electron mass in the band gap of the dielectric $\left(m_{o x}=0.37 m_{e}\right.$ for $\mathrm{SiO}_{2}$ [26]), $m_{e}$ is the free electron mass, $h$ is the Planck's constant, $q$ is the electron charge and $\Phi_{B}$ is the energy barrier height.

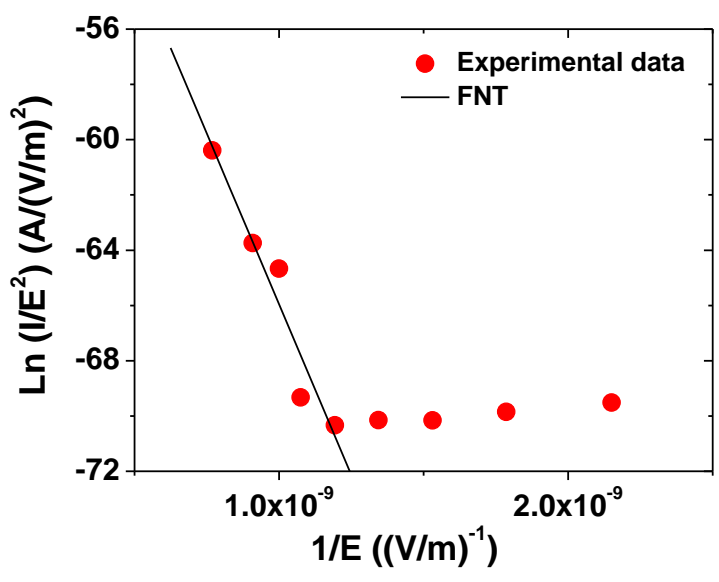

Figure 9. FNT plot for the 6 nm-thick $\mathrm{SiO}_{\mathrm{x}} \mathrm{N}_{\mathrm{y}}$ sample.

Figure 9 represents the FNT plot for the $6 \mathrm{~nm}$-thick $\mathrm{SiO}_{\mathrm{x}} \mathrm{N}_{\mathrm{y}}$ sample after fitting the experimental data at high electric field to equation (6). This procedure permits to extract parameters as injection barrier $\Phi_{\mathrm{B}}$ and contact surface. Accordingly, an energy barrier $\Phi_{\mathrm{B}}$ of $3.28 \mathrm{eV}$ was found. It is in agreement with values reported in the literature, from 2.25 to $3.34 \mathrm{eV}$ for $\mathrm{SiO}_{2}$ layers [26]. For comparison purposes, the Schottky barrier height (SBH) was calculated in the frame of the metal-induced gap states theory accounting for the charge transfer at the metal-dielectric contact $[36,37]$. By applying the Schottky pinning parameter $S_{p}=0.887$, as obtained after considering the extracted from spectroscopic ellipsometry measurements electronic part of the dielectric permittivity ( $\$ 3.1$ ), the $\mathrm{SBH}$ for electrons was found $3.87 \mathrm{eV}$. 
However, the achieved correlation coefficient of the FNT fit is poor, of only 0.92. It leads to a quite high error interval for the contact surface, ranging from $2.4 \times 10^{4} \mathrm{~nm}^{2}$ to $3.7 \times 10^{7} \mathrm{~nm}^{2}$, when taking into account the standard deviation of the intercept. Considering the effective surface as $S_{\text {eff }}=\pi R_{c}{ }^{2}$, the corresponding collection surface ranges from $0.5 \times S_{\text {eff }}$ to $760 \times S_{\text {eff }}$.

Neither of the above presented approaches is really convincing in our case. Indeed, the effective contact surface seems to be an adjustment parameter whose physical significance is not straightforward. Considering only mechanical contact is a limitation because it does not take into account the possibility to collect charges by "proximity", that is to say through air by the curvature of the AFM-tip. Such situation was already demonstrated. Dielectric layers can be charged in "tip-to-sample" space mode, i.e. charges are injected without contact between the tip and the dielectric surface over a distance of around $50 \mathrm{~nm}[45,46]$. However, the charge collection efficiency strongly depends on the distance to contact point. The latter is in agreement with the presented experimental results.

\section{- Thin dielectric layers $(15 \mathrm{~nm}<d<150 \mathrm{~nm})$}

To analyze the results for thin $\mathrm{SiO}_{\mathrm{x}} \mathrm{N}_{\mathrm{y}}$-layers $(15 \mathrm{~nm}<d<150 \mathrm{~nm})$, the current measured in a classical MIM configuration is completed by the C-AFM results. The MIM measurements were performed under controlled atmosphere. The potential $\mathrm{V}_{\mathrm{dc}}$ was applied by steps and the current was measured for $1000 \mathrm{~s}$ on a $116.8 \mathrm{~nm}$ thick $\mathrm{SiO}_{\mathrm{x}} \mathrm{N}_{\mathrm{y}}$ layer. The C-AFM measurements were performed on the $50 \mathrm{~nm}$-thick $\mathrm{SiO}_{\mathrm{x}} \mathrm{N}_{\mathrm{y}}$-layer and the current density was obtained after dividing the measured current by an effective contact area $\left(\mathrm{S}_{\mathrm{eff}}\right)$. The upper electrode (probe), is represented by a disk with radius equal to the curvature radius of the tip $\left(\mathrm{R}_{\mathrm{c}}=125 \mathrm{~nm}\right)$. To test the reliability of the procedure and to account for the uncertainty in the effective collection area, the estimation of the current density is completed in the hypothesis of a collection surface 10 and 100 times larger than the $S_{\text {eff. }}$ The obtained results are presented in figure 10. Comparison between C-AFM and classical MIM configuration is tough, as applied electric field in the two cases are very different; homogeneous versus inhomogeneous one, with strongly pronounced strengthening at the AFM tip. However, the measured current densities seem consistent with transport mechanisms described by an ohmic behavior at low field, a threshold field of $10^{8} \mathrm{~V} / \mathrm{m}$ which is represented by a change in slope in the log-log diagram, and a high field region where the C-AFM points appear rational with the overall. However, measurements for electric fields in-between these two extremities must be performed to complete and confirm the described trend. Even though the overall picture seems consistent, taking into account of different $S_{\text {eff }}$ raises the problem of the effective contact surface between the AFM-tip and the sample. The 
contact surface can then be used as an adjustable parameter for each experiment. Indeed, studies reported in the literature show that for C-AFM measurements, the contact surfaces should be taken several order greater than the presumed one, a disk with a radius equal to the AFM-tip curvature radius [27-29].

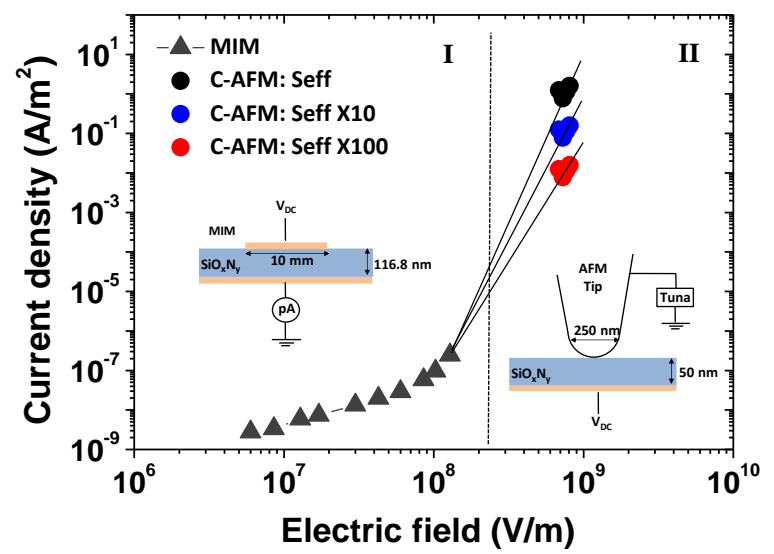

Figure 10. Current density variation for low and high electric fields: I) classical MIM measurements on $116.8 \mathrm{~nm}$ thick layer, II) C-AFM measurements on $50 \mathrm{~nm}$ thick layer.

Despite the simplicity of the above presented approach, the obtained results underline that a quantitative interpretation of the C-AFM measurements of inorganic thin dielectric layers requires assessment of the collecting surface and consideration of the current density heterogeneity. The same outcome was reached in the case of organic semiconductors [41]. Present results suggest further complexity brought by charge trapping near the AFM tip. The electric field near the tip is obviously modified by the stored charge, by amounts of the order of the applied field by considering the electrostatic modelling made with $2 \mathrm{D}$ or $3 \mathrm{D}$ charge clouds. Because of these charge trapping effects, injected charges can flow radially over reasonable distance before being collected in the bulk. It means that the apparent collecting surface would have a dynamic character in addition to the uncertainty about its extension.

\subsection{Charge dissipation after injection: time evolution for ultrathin and thin $\mathrm{SiO}_{x} \mathrm{~N}_{y}$-layers}

We finally consider how the potential profiles evolve in time after charge storage to approach charge dissipation processes. Figure 11 represents the evolution of the potential profile, recorded at different times after injection. Again the ultrathin and thin $\mathrm{SiO}_{\mathrm{x}} \mathrm{N}_{\mathrm{y}}$-layers behave differently. For the ultrathin $\mathrm{SiO}_{\mathrm{x}} \mathrm{N}_{\mathrm{y}}$-layers the surface potential baseline at the end of the injection process is at higher level compared to the surface potential before the charging step. Then a rapid decrease of the reference baseline of the surface potential is observed in time, as shown for the 
$11 \mathrm{~nm}$-thick $\mathrm{SiO}_{\mathrm{x}} \mathrm{N}_{\mathrm{y}}$-layer (figure 11(a)). The surface potential baseline reaches a level close to the initial one, i.e. that the surface potential before charge injection, after $500 \mathrm{~s}$.

The thin dielectric layers are characterized by no modifications of the reference surface potential at the end of the injection with respect to the values before injection. The reference surface potential remains at the same level after injection too, whereas a decrease of the surface potential maximum of the profile occurs, as given for the $31 \mathrm{~nm}$-thick $\mathrm{SiO}_{\mathrm{x}} \mathrm{N}_{\mathrm{y}}$-layer (figure 11(b)).
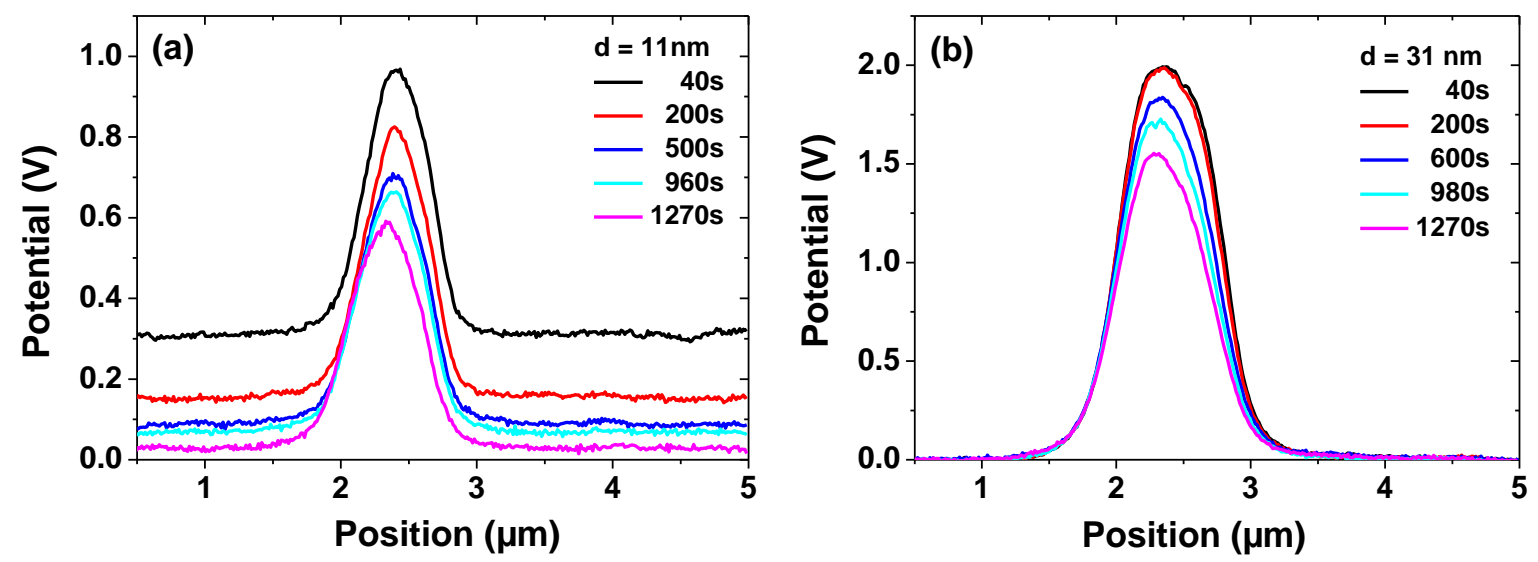

Figure 11. Evolution of potential profiles with time after injection for (a) ultrathin (11 nm-thick $\left.\mathrm{SiO}_{\mathrm{x}} \mathrm{N}_{\mathrm{y}}\right)$ and (b) thin (31 nm-thick $\mathrm{SiO}_{\mathrm{x}} \mathrm{N}_{\mathrm{y}}$ ) dielectric layers (injection at $\mathrm{V}_{0}=+12 \mathrm{~V}$ during $4 \mathrm{~min}$ ).

A way to better understand these phenomena is to follow the evolution of the surface potential profile baseline as function of time after injection for different layer thicknesses, as shown in figure 12(a). The results confirm the strong modification of the surface potential profile baseline occurring during the charging step, followed by recovery of the initial level for ultrathin layers (the $11 \mathrm{~nm}$-thick $\mathrm{SiO}_{\mathrm{x}} \mathrm{N}_{\mathrm{y}}$ on figure 12(a)) due to charge relaxation on Au-electrode. The observed phenomenon for ultrathin layers is actually attributed to charges collection in the buried $\mathrm{Au}$-electrode which is at floating potential during the injection step (as shown in insert of figure 12(a)). Increasing the $\mathrm{SiO}_{\mathrm{x}} \mathrm{N}_{\mathrm{y}}$-layer thickness leads to disappearance of this effect, as confirmed for thin $\mathrm{SiO}_{x} \mathrm{~N}_{y}$-layers (the $31 \mathrm{~nm}$-thick $\mathrm{SiO}_{\mathrm{x}} \mathrm{N}_{\mathrm{y}}$ on figure 12(a)). It means that for thin $\mathrm{SiO}_{\mathrm{x}} \mathrm{N}_{\mathrm{y}^{-}}$ layers $(15 \mathrm{~nm}<d<150 \mathrm{~nm})$ the injected charges do not reach the Au-floating electrode. They are trapped in the dielectric layer close to the contact area. The recorded surface potential profile baseline repeats the one before charge injection, and remains the same during the charge injection step.

These results actually provide information about the charges penetration depth. Indeed, the penetration depth is one of the key parameters to know aiming at extraction of the charges 
density from surface potential measurement [40]. According to the obtained results on the reference surface potential, one can conclude that the charge penetration depth is limited to the thickness of ultrathin dielectric layers $(d<15 \mathrm{~nm})$, thus confirming the assumption made in Section 3.4 for charge penetration depth of $10 \mathrm{~nm}$. The invariance of the reference surface potential for thin layers $(15 \mathrm{~nm}<d<150 \mathrm{~nm})$ validates the hypothesis of in-depth charge spreading independent from the layer thickness.
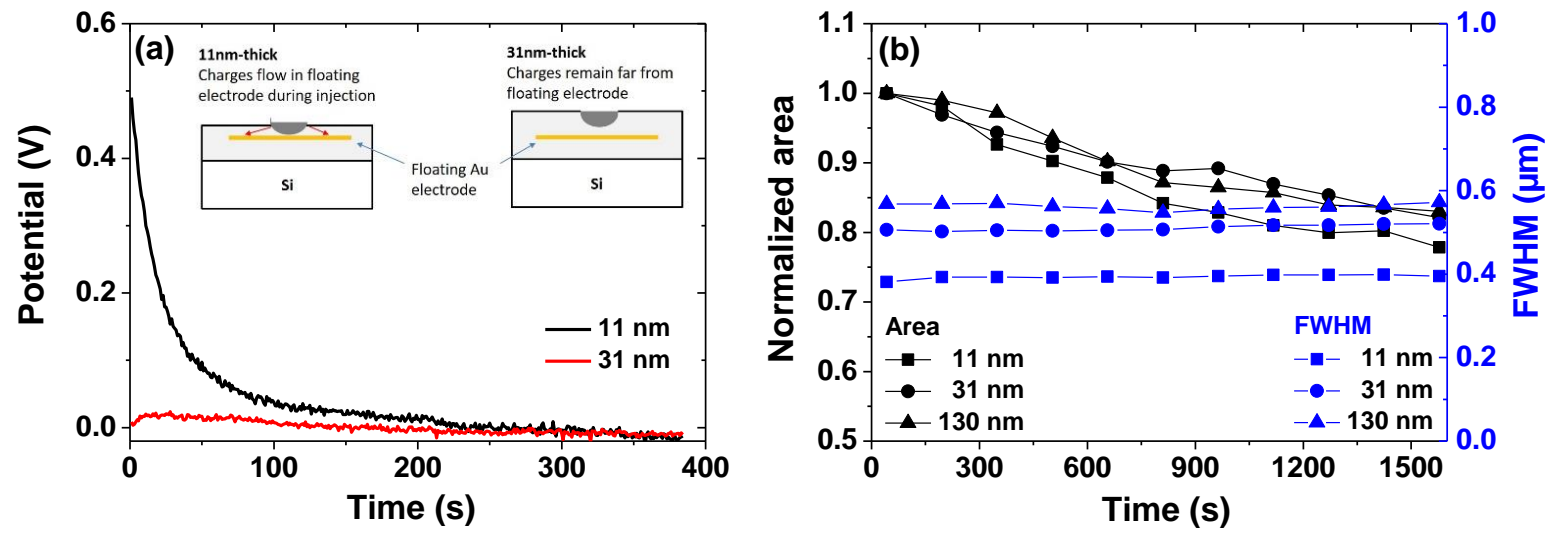

Figure 12. (a) Reference surface potential evolution in time after charge injection for ultrathin and thin $\mathrm{SiO}_{x} \mathrm{~N}_{\mathrm{y}}$ films (11 nm-thick and $31 \mathrm{~nm}$-thick $\mathrm{SiO}_{\mathrm{x}} \mathrm{N}_{\mathrm{y}}$ films), (b) Evolution in time after charge injection of the FWHM and the surface potential profile normalized area, with respect to its initial value, for different film thicknesses. The same charge injection conditions are used in each case: 2 min at $\mathrm{V}_{0}=+5 \mathrm{~V}$.

As far as the time evolution of the other characteristics of the surface potential profile after charge injection, one can observe the same trends for the FWHM and the normalized area with respect to its initial values (figure 12(b)). Regardless the $\mathrm{SiO}_{\mathrm{x}} \mathrm{N}_{\mathrm{y}}$-layer thickness the FWHM of the surface potential profile remains constant in time and the normalized area decreases with the same linear dynamic meaning that the dielectric film thickness does not affect the dissipation behavior of the injected electrical charges. Even for the ultrathin $\mathrm{SiO}_{\mathrm{x}} \mathrm{N}_{\mathrm{y}}$-layers (the $11 \mathrm{~nm}$-thick $\mathrm{SiO}_{\mathrm{x}} \mathrm{N}_{\mathrm{y}}$ on figure 12(b)) the trapped charges remain stable. The same charge dissipation behavior determines decay mechanisms being function of the material properties only and not of the layer geometrical aspect; ultrathin or thin $\mathrm{SiO}_{\mathrm{x}} \mathrm{N}_{\mathrm{y}}$-layers. The observed linearly decaying area and constant FWHM of the surface potential after charge injection confirm a charge dissipation mechanism preferentially occurring in the volume of the dielectric layer.

\section{Conclusion}

The influence of the thickness of thin plasma deposited silicon oxynitride $\mathrm{SiO}_{\mathrm{x}} \mathrm{N}_{\mathrm{y}}$ layers on the charge injection mechanisms was investigated in KPFM mode at nanoscale for different applied 
DC-voltages and injection times. The $\mathrm{SiO}_{\mathrm{x}} \mathrm{N}_{\mathrm{y}}$ layers are structurally identical for all thicknesses. The $\mathrm{SiO}_{\mathrm{x}} \mathrm{N}_{\mathrm{y}}$ layers are well structured, optically transparent, and having refractive index $\mathrm{n}=1.45$, equal to the one of silica. Analysis of the recorded surface potential profiles, after performed charge injection, shows distinguished behavior for ultrathin $(d<15 \mathrm{~nm})$ and thin $(15 \mathrm{~nm}<d<150 \mathrm{~nm})$ dielectric layers. The same is observed for both increased bias voltage and increased injection time. To explain the observed trends a 2D-axisymetric electrostatic model is developed on FEM basis. The FEM modelling emphasizes that during the charge injection step the electric field in the dielectric layer is divergent and strongly enhanced close to the injection point. This enhancement is less pronounced for the ultra-thin dielectric layers for which the dielectric thickness becomes comparable to the curvature radius of the AFM tip. The electric field decreases exponentially in the dielectric layer. The radial electric field component is strong, giving rise to charge spreading in radial direction. The electric field at the contact point determines the amount of injected charges in the dielectric layer. The injected charges are localized close to the injection point. Their penetration depth in the oxynitride dielectric layer in the order of $10 \mathrm{~nm}$. Current versus voltage curves were obtained locally in C-AFM mode. An injection barrier of $3.28 \mathrm{eV}$ has been extracted from FNT plots. Again the ultra-thin and the thin $\mathrm{SiO}_{\mathrm{x}} \mathrm{N}_{\mathrm{y}}$ layers behave differently, with mixed behavior for the dielectric layer with thickness in the transition between the two groups. The fast increase in current at high field could be related to Fowler-Nordheim effect. However, incertitude about effective collection surface in C-AFM, configuration of divergent field and probable space charge induced modification of the local field make quantitative assessment tricky. The collection surface seems to have a dynamic character in addition to the uncertainty about its extension. Analysis of charge dissipation in the dielectric layers confirms the second hypothesis for bell-shape distribution of the amount of injected charges in both axial and radial directions and the considered in the model charge penetration depth. Further work will be directed to edge effects induced by the discontinuity of the metal electrode and to analyses of energetics of injected charges, and description of charge trapping and transport in these silica-like $\mathrm{SiO}_{\mathrm{x}} \mathrm{N}_{\mathrm{y}}$ layers.

\section{Acknowledgments}

This work has been supported by Région Midi-Pyrénées under contract Reference 10051265 and by the program IDEX Actions Thématiques Stratégiques - ATS 2015 of the Université de Toulouse under project SEPHIR (2016-066-CIF-D-DRVD). 


\section{References}

[1] Rao R A, Steimle R F, Sadd M, Swift C T, Hradsky B and Straub S 2004 Silicon nanocrystal based memory devices for NVM and DRAM applications Solid-State Electron. 48, 1463

[2] Perret-Tran-Van S, Makasheva K, Despax B, Bonafos C, Coulon P E and Paillard V 2010 Controlled fabrication of Si-nanocrystals embedded in thin SiON layers by PPECVD followed by oxidizing annealing Nanotechnology 21, 28560

[3] Witvrouw A, Tilmans H A C and De Wolf I 2004 Materials issues in the processing, the operation and the reliability of MEMS Microelectronic Engineering 76, 245-257

[4] http://www.esda.org/

[5] Rezende C A, Gouveia R F, da Silva M A and Galembeck F 2009 Detection of charge distribution in insulator surfaces J. Phys.: Condens. Matter 21, 263002

[6] Lamhamdi M, Pons P, Zaghloul U, Boudou L, Coccetti F, Guastavino J, Segui Y, Papaioannou G and Plana R 2008 Voltage and temperature effect on dielectric charging for RF-MEMS capacitive switches reliability investigation Microelectronics Reliability 48, 1248

[7] Zhang W M, Meng G and Chen D 2007 Stability, nonlinearity and reliability of electrostatically actuated MEMS devices Sensors 7, 760

[8] Teyssedre G, Villeneuve C, Pons P, Boudou L, Makasheva K and Despax B 2012 Challenges in probing space charge at sub-micrometer scale Annual Report IEEE Conference on Electrical Insulation and Dielectric Phenomena (CEIDP) 234

[9] Hamidouche L, Geron E and Hole S 2017 Very high spatial resolution space charge measurement using electro-acoustic reflectometry (EAR) IEEE Electr. Insul. Mag. 33-5, 9.

[10] Arita Y, Shiratori S and Ikezaki K 2003 A method for detection and visualization of charge trapping sites in amorphous parts in crystalline polymers J. Electrostatics 57263

[11] Stern J E, Terris B D, Mamin H J and Rugar D 1988 Exposition and imaging of localized charge on insulator surfaces using force microscope Appl. Phys. Lett. 53, 2717

[12] Marchi F, Dianoux R, Smilde H J H, Mur P, Comin F and Chevrier J 2008 Characterization of trapped electric charge carriers behavior at nanometer scale by electrostatic force microscopy Journal of Electrostatics 66, 538

[13] Lambert J, de Loubens G, Guthmann C and Saint-Jean M 2002 Dispersive charge transport along the surface of an insulating layer observed by electrostatic force microscopy Phys. Rev. $B$ 71, 15 
[14] Tzeng S-D and Gwo S 2006 Charge trapping properties at silicon nitride/silicon oxide interface studied by variable-temperature electrostatic force microscopy J. Appl. Phys. 100, 023711

[15] Morita S, Uchihashi T, Okamoto K, Abe M and Sugawara Y 2005 Microscale contact charging on silicon oxide Characterization, Nanofabrication and Device Application of Functional Materials 186, 289

[16] Charrier D S H, Kemerink M, Smalbrugge B E, Vries T and Janssen R A J 2008 Real versus measured surface potentials in scanning Kelvin Probe Microscopy ACS Nano 2,622

[17] Borowik L, Kusiaku K, Theron D and Melin T 2010 Calculating Kelvin force microscopy signals from static force fields Appl. Phys. Lett. 96, 103119

[18] Ishii M. 2010 Static states and dynamic behaviour of charges: observation and control by scanning probe microscopy J. Phys.: Condens. Matter 22, 173001.

[19] Zaghloul U, Bushan B, Pons P, Papaioannou G J, Coccetti F and Plana R 2011 On the influence of environment gases, relative humidity and gas purification on dielectric charging/discharging processes in electrostatically driven MEMS/NEMS devices Nanotechnology 22, 035705

[20] Zaghloul U, Bushan B, Pons P, Papaioannou G J, Coccetti F and Plana R 2010 A systematic reliability investigation of the dielectric charging process in electrostatically actuated MEMS based on Kelvin Force Microscopy J. Micromech. Microeng. 20, 064016

[21] Ziegler D, Naujoks N and Stemmer A 2008 Feed-forward compensation of surface potential in atomic force microscopy Review of Sci. Instrum. 79, 063704

[22] Lanza, M. 2017 Conductive Atomic Force Microscopy: Applications in Nanomaterials Wiley-VCH Verlag: Weinheim, Germany

[23] Foissac R, Blonkowski S, Kogelschatz M, and Delcroix P 2014 A relationship between statistical time to breakdown distributions and pre-breakdown negative differential resistance at nanometric scale J. Appl. Phys.116, 024505

[24] Seko A, Watanabe Y, Kondo H, Sakai A, Zaima S and Yasuda Y 2004 Behavior of Local current leakage in stressed gate $\mathrm{SiO}_{2}$ films analyzed by Conductive Atomic Force Microscopy Jpn J. Appl.Phys. 43, 4683

[25] Frammelsberger W, Benstetter G, Kiely J and Stamp R 2007 C-AFM-based thickness determination of thin and ultra-thin $\mathrm{SiO}_{2}$ films by use of different conductive-coated probe tips Appl. Surf. Sci. 253, 3615 
[26] Frammelsberger W, Benstetter G, Stamp R, Kiely J and Schweinboeck T 2005 Simplified tunnelling current calculation for MOS structures with ultra-thin oxides for conductive atomic force microscopy investigations Materials Science and Engineering B 116, 168

[27] Olbrich A, Ebersberger N and Boit C 2001 Nanoscale electrical characterization of thin oxides with conductive atomic force microscopy 36th annual IEEE IRPS, 2934

[28] Porti M, Nafra M, Aymerich X, Olbrich A and Ebersberger B 2001 Nanometer-scale electrical characterization of stressed ultra-thin $\mathrm{SiO}_{2}$ film using conducting atomic force microscopy Appl. Phys. Lett. 78, 4181

[29] Olbrich A, Ebersberger B, Boit C, Vancea J and Hoffmann H 1999 A new AFM-based tool for testing dielectric quality and reliability on a nanometer scale Microelectronics Reliab. 39, 941

[30] Makasheva K, Despax B, Boudou L and Teyssedre G 2012 Dielectric layers for RF-MEMS switches: design and study of appropriate structures preventing electrostatic charging IEEE Trans. Dielectrics and Electrical Insulation 19, 1195

[31] Villeneuve-Faure C, Makasheva K, Bonafos C, Despax B, Boudou L, Pons P and Teyssedre G 2013 Kelvin force microscopy characterization of charging effect in thin a$\mathrm{SiO}_{\mathrm{x}} \mathrm{N}_{\mathrm{y}}: \mathrm{H}$ layers deposited in pulsed plasma enhanced chemical vapor deposition process by tuning the silicon environment J. Appl. Phys. 113, 204102

[32] WinElli Software by SOPRA S.A. Version 3.041999

[33] Forouhi A R and Bloomer I 1986 I Optical dispersion relations for amorphous semiconductors and amorphous dielectrics Phys. Rev. B 34, 7018-7026

[34] Wang Y and Irene E A 2000 Consistent refractive index parameters for ultrathin $\mathrm{SiO}_{2}$ films J. Vac. Sci. Technol. B, 18, 279-282

[35] Radouane K, Date L, Yousfi M, Despax B and Caquineau H 2000 RF discharge modelling in a $\mathrm{N}_{2} \mathrm{O} / \mathrm{SiH}_{4}$ mixture for $\mathrm{SiO}_{2}$ deposition and comparison with experiment J. Phys. D: Appl. Phys. 33 1332-1341

[36] Robertson $\mathrm{J}$ and Falabretti B 2006 Band offsets of high $K$ gate oxides on III-V semiconductors J Appl. Phys., 100, 014111

[37] Villeneuve-Faure C, Makasheva K, Boudou L, and Teyssedre G 2016 Charge injection in thin dielectric layers by atomic force microscopy: influence of geometry and material work function of the AFM tip on the injection process Nanotechnology 27, 245702

[38] Boularas A, Baudoin F, Villeneuve-Faure C, Clain S and Teyssedre G 2014 Multidimensional modelling of electrostatic force distance curve over dielectric surface: Influence of tip geometry and correlation with experiment J. Appl. Phys. 116, 084106 
[39] Sacha G M, Cardellach M, Segura J J, Moser J, Bachtold A, Fraxedas J and Verdaguer A 2009 Influence of the macroscopic shape of the tip on the contrast in scanning polarization force microscopy images Nanotechnology 20, 285704

[40] Palleau E, Ressier L, Borowik $Ł$ and Mélin T 2010 Numerical simulations for a quantitative analysis of AFM electrostatic nanopatterning on PMMA by Kelvin force microscopy Nanotechnology 21, 225706

[41] Reid O G, Munechika K and Ginger D S 2008 Space charge limited current measurements on conjugated polymer films using Conductive Atomic Force Microscopy NanoLetters 8, 1602

[42] Hebert K J, Zafar S, Irene E A, Kuehn R, McCarthy T E and Demirlioglu E K 1996 Measurement of the refractive index of thin $\mathrm{SiO}_{2}$ films using tunneling current, oscillations and ellipsometry Appl. Phys. Lett. 68, 266

[43] Ruskell TG, Workman R, Chen D, Sarid D, Dalh A and Gilbert S 1996 High-resolution Fowler-Nordheim field emission map of thin silicon oxide layers Appl. Phys. Lett. 68, 93

[44] Celano U, Hantschel T, Giammaria G, Chandra Chintala R, Conard T, Bender H and Vandervorst W 2015 Evaluation of the electrical contact area in contact-mode scanning probe microscopy J. Appl. Phys. 117, 214305

[45] Ressier L and Le Nader V 2008 Electrostatic nanopatterning of PMMA by AFM charge writing for directed nano-assembly Nanotechnology 19, 135301

[46] Makasheva K, Villeneuve-Faure C, Laurent C, Despax B, Boudou L and Teyssedre G 2015 Dielectric charging by AFM in tip-to-sample space mode: overview and challenges in revealing the appropriate mechanisms Nanotechnology 26, 295704 